Portland State University

PDXScholar

$12-4-1997$

\title{
Examination of Benefits of Binaural Auditory \\ Stimulation for Children with a Cochlear Implant and a Hearing Aid in the Contralateral Ear
}

Evonne Nicol Altesleben

Portland State University

Follow this and additional works at: https://pdxscholar.library.pdx.edu/open_access_etds

Part of the Speech and Hearing Science Commons

Let us know how access to this document benefits you.

\section{Recommended Citation}

Altesleben, Evonne Nicol, "Examination of Benefits of Binaural Auditory Stimulation for Children with a Cochlear Implant and a Hearing Aid in the Contralateral Ear" (1997). Dissertations and Theses. Paper 5822.

https://doi.org/10.15760/etd.7693

This Thesis is brought to you for free and open access. It has been accepted for inclusion in Dissertations and Theses by an authorized administrator of PDXScholar. Please contact us if we can make this document more accessible: pdxscholar@pdx.edu. 


\section{THESIS APPROVAL}

The abstract and thesis of Evonne Nicol Altesleben for the Master of Science in Speech Communication: Speech and Hearing Science were presented December 4, 1997, and accepted by the thesis committee and the department.

COMMITTEE APPROVALS:
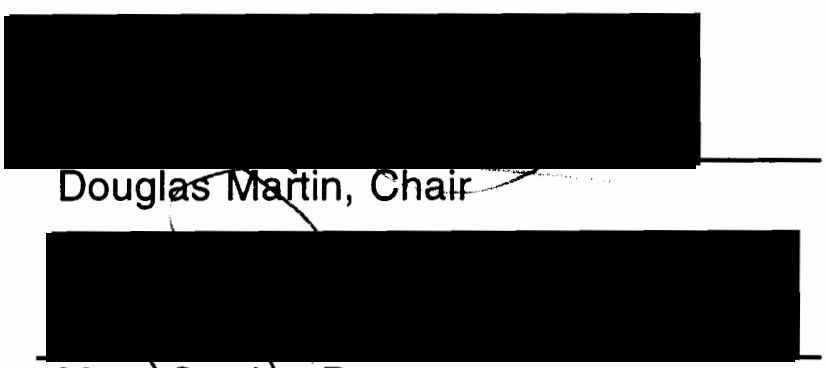

Mary Gorddn-Brannon

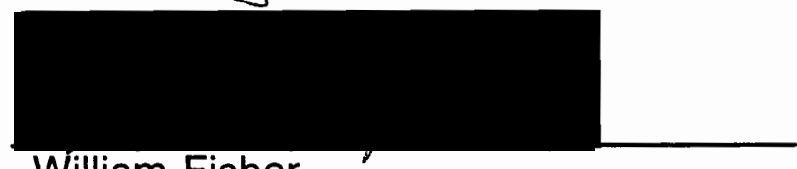

William Fisher

Representative of the Office

of Graduate Studies

DEPARTMENT APPROVAL:

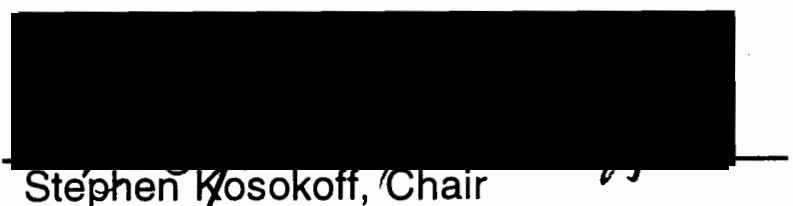

Department of Speech Communication 
ABSTRACT

An abstract of the thesis of Evonne Nicol Altesleben for the Master of Science in Speech Communication: Speech and Hearing Science presented December 4, 1997.

Title: Examination of benefits of binaural auditory stimulation for children with a cochlear implant and a hearing aid in the contralateral ear.

Congenital or acquired hearing impairments put children at risk of delayed language development. Today the cochlear implant $(\mathrm{Cl})$ is a viable amplification option for some children with profound hearing losses. Audiologists often recommend that children with hearing impairments be fitted with binaural hearing aids in the hope that maximum stimulation will occur and that auditory deprivation will be lessened. An area lacking investigation is whether binaural stimulation will be beneficial to the cochlear implant recipient. Controversy also exists regarding the use of a hearing aid in the non-implanted ear.

The focus of this study was to compare binaural auditory stimulation benefits for children who have a $\mathrm{Cl}$ and a hearing aid in the non-implanted ear with those children who use the implant alone using a group statistical design. Fourteen children with a $\mathrm{Cl}$ and also enrolled in an auditory-oral 
training program took part in this study. Eight of these children also wear a hearing aid in the non-implanted ear. The investigation incorporated the Early Speech Perception Test (ESP) to assess the auditory perception abilities of children in the two groups.

The results of the regression analysis revealed that duration of $\mathrm{Cl}$ use did not significantly impact subtest scores on the ESP test. Regression analysis also revealed a significant difference in scores between the two groups at the .05 level on the standard pattern/perception and word identification tests while no significant differences were noted between the groups on the spondee identification and monosyllable identification tests. The difference noted between the groups on the standard pattern/perception and word identification tests could have been influenced by the low level of processing skills required to complete the tasks.

The results of the current investigation, at least as presented in this study, revealed that the auditory perception performance of the $\mathrm{Cl}$ and $\mathrm{Cl}+$ hearing aid groups were similar and no significant difference was noted overall on the ESP test, though there were some significant differences in certain subtests. If nothing else, this study supports the use of both devices with no adverse effects on performance. 
EXAMINATION OF BENEFITS OF BINAURAL AUDITORY STIMULATION

FOR CHILDREN WITH A COCHLEAR IMPLANT AND A

HEARING AID IN THE CONTRALATERAL EAR

by

EVONNE NICOL ALTESLEBEN

A thesis submitted in partial fulfillment of

the requirements for the degree of

\author{
MASTER OF SCIENCE \\ in \\ SPEECH COMMUNICATION \\ SPEECH AND HEARING SCIENCE
}

Portland State University

1998 


\section{THIS THESIS IS DEDICATED TO MY SISTER}

\section{Ellen Michele Altesleben}

Her abundance of love, caring, faith, and support encouraged me to continue with my educational endeavors. It is her confidence, enthusiasm and spirit that I will carry with me, forever in my heart.

LOVE ALWAYS 


\section{SPECIAL ACKNOWLEDGMENT}

Special thanks and love go to Michael R. Serpa. Thank you for being an invaluable source of love, support, encouragement, and advice throughout this thesis process, as well as my entire educational pursuits.

Get ready for the next adventure! 


\section{ACKNOWLEDGMENTS}

My greatest thanks and appreciation go to everyone who has helped me in any way with this endeavor. Special thanks go to my committee members, including my advisor, Dr. Doug Martin, who showed tremendous support and direction throughout the study. Thanks to the other members, Dr. Mary Gordon-Brannon, for her helpful advice during this project and critique on the rough draft, and Dr. William Fisher, for his helpful insights that added greatly to the project. Thanks also to Ellen Reuler for attending the defense for Mary Gordon-Brannon on such short notice and providing key suggestions to the finished document.

Special thanks also go to Arlie Adam, Audiologist at Tucker Maxon Oral School, for providing access to subjects for the study, and contributing her time, insight, knowledge and abundance of encouragement. Also thanks to the other faculty members at PSU, Maria M. Hopple and Dr. Tom Dolan for helping to make my experience at PSU challenging and rewarding. 


\section{TABLE OF CONTENTS}

PAGE

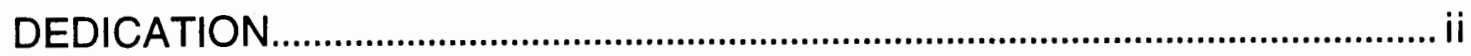

SPECIAL ACKNOWLEDGMENT......................................................................

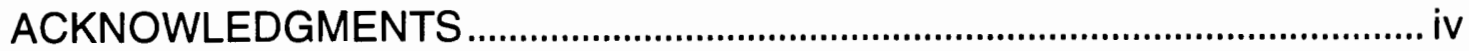

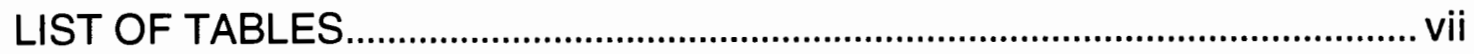

CHAPTERS

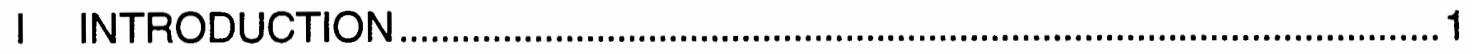

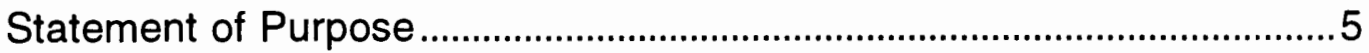

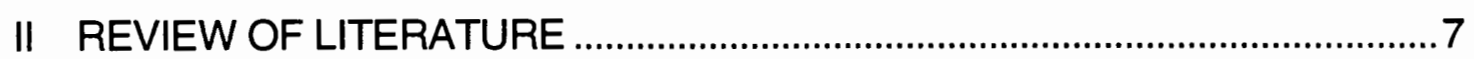

Auditory Perception/Hearing Impaired Children .......................................

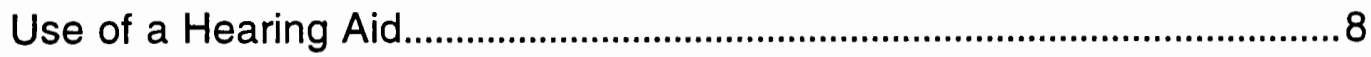

The Cochlear Implant ...............................................................................11

Cochlear Implant Auditory Perception....................................................13

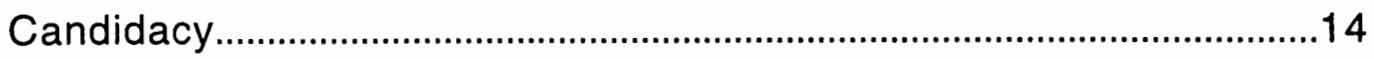

Binaural Amplification for $\mathrm{Cl}$ users .........................................................16

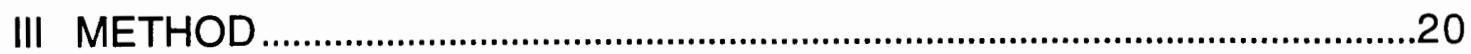

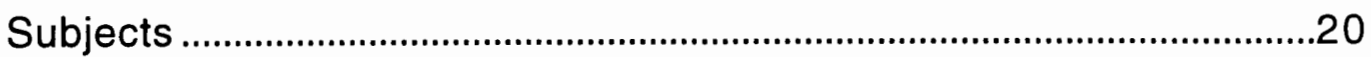

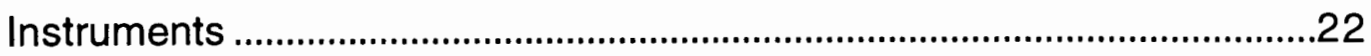

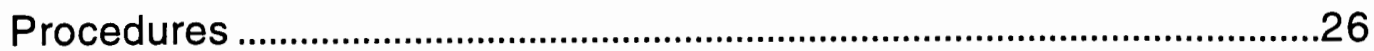

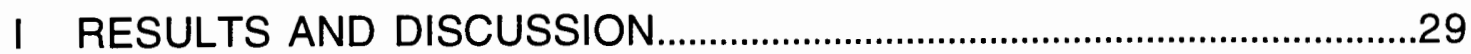




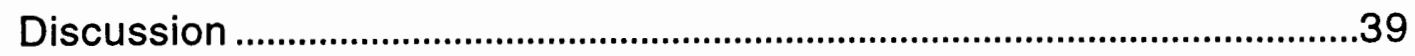

I CHAPTER 5

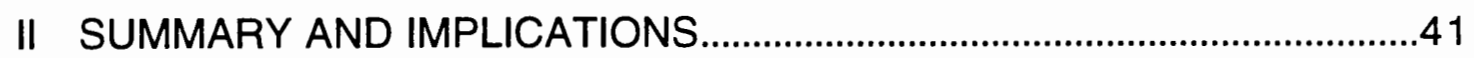

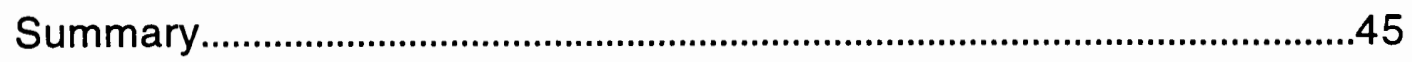

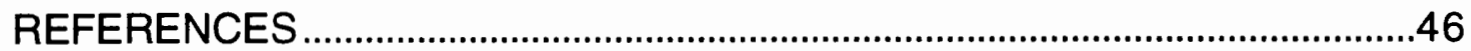




\section{LIST OF TABLES}

TABLE

Candidacy Requirements for Cochlear Implants

Subject Profile.

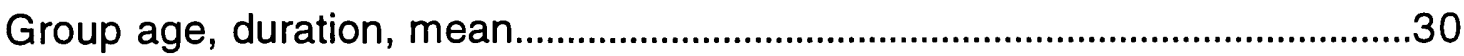

Regression Analysis Relationship of Duration of Implant Usage and Subtest between Groups

Data of ESP Subtests for Group 1 ( $\mathrm{Cl}$ only) …..................................................33

Data of ESP Subtests for Group $2(\mathrm{Cl}+$ Hearing aid) ....................................33

Regression Analysis for the ESP Standard Pattern/Perception test................34

Regression Analysis for the ESP Word Identification test..................................34

Regression Analysis for the ESP Spondee Identification test .........................34

Regression Analysis for the ESP Monosyllable Identification test....................34

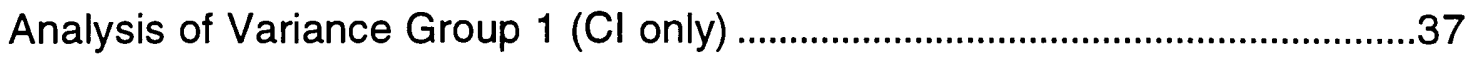

Analysis of Variance Group $2(\mathrm{Cl}+$ Hearing aid) ..............................................37

Tukey's Pairwise Comparison Group 1 (Cl only) …........................................38

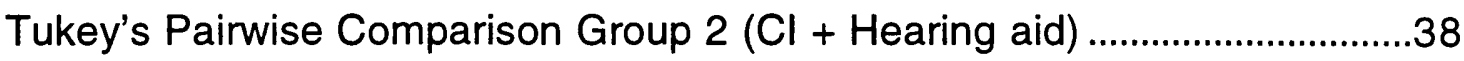




\section{CHAPTER 1}

INTRODUCTION

Congenital or acquired hearing impairments put children at risk of delayed language development. In view of this, it is important to make an early diagnosis of a child's hearing impairment. The American SpeechLanguage-Hearing Association (ASHA) approved the Infant Hearing Position Statement proposed by the Joint Committee on Infant Hearing in 1990. This proposal stated that educational and medical intervention aids in the development of optimal communication and social skills in children, and requires early identification of hearing impairments (National Institute of Health, 1995). With current advances in technology, many mechanisms exist to identify a hearing loss for very young children. Nevertheless, hearing loss typically is not detected until children are 13 to 24 months of age, which can delay language learning (Northern \& Downs, 1991).

Chmiel, Clark, Jerger, Jenkins and Freeman (1995) noted that when the ear is deprived of adequate sound stimulation, the ability of the auditory system to process speech diminishes; the longer auditory language stimulation is delayed, the less efficient language usage will be. For children who are hearing impaired, adequate auditory stimulation during their language learning years will aid in diminishing the effects of auditory deprivation while increasing their ability to develop communication strategies necessary for adult skills (Northem \& Downs, 1991). 
Conventional hearing aids represent the traditional means of amplifying sound for children with hearing impairments. Audiologists often recommend that children with hearing impairments be fitted with binaural hearing aids in the hope that maximum stimulation will occur and that auditory deprivation will be lessened. Some children with profound sensorineural hearing losses, however, do not benefit from the use of these traditional amplification devices. Today the cochlear implant $(\mathrm{Cl})$ is a viable amplification option for these children.

$\mathrm{A} \mathrm{Cl}$ is a surgically implanted coiled array of electrodes designed to provide a sensation of sound for an individual with a profound bilateral sensorineural hearing loss. Over the years both single electrode arrays and multiple electrode arrays have been developed and tested on adults and children (Geers \& Moog, 1994). The electrode array is placed in the cochlea and attached to a microelectronic processor buried under the skin behind the ear. The implanted electrodes are used in association with a body-worn speech processor.

Implants provide an awareness of sound, but do not restore normal hearing to individuals who are deaf (Shipley \& McAfee, 1992). Performance varies with each individual and type of $\mathrm{Cl}$ used. Effects recorded range from very effective, providing the ability to distinguish complex sounds like music 
and speech perception skills like performance on open-set tests, to useful only in assistive speech reading situations.

Specific criteria must be met before approval for fitting of a cochlear implant for a child. FDA regulations stipulate children must be no younger than 2 years of age, have a profound sensorineural hearing loss in both ears, have appropriate expectations (e.g., cost, maintenance, and rehabilitative process) for the child and the family, and have access to an educational program that will emphasize the development of auditory skills after the implant has been fitted. Another important criterion for children is a documented trial period which shows little or no benefit from conventional hearing aids.

$\mathrm{Cls}$ are implanted only monaurally and an area lacking investigation is whether binaural stimulation will be beneficial to the cochlear implant recipient with the use of a hearing aid in the non-implanted ear. Some parents, audiologists, and teachers have questioned whether binaural stimulation will be beneficial to the $\mathrm{Cl}$ recipient given that performance was minimal with a hearing aid alone (Chmiel et al., 1995). Also, some children with a $\mathrm{Cl}$ continue to wear a hearing aid in the non-implanted ear even though there is a lack of evidence to support binaural stimulation in the cochlear implant population. Chmiel et al. (1995) studied children who had profound sensorineural hearing losses and received very minimal benefit 
from a hearing aid before receiving a $\mathrm{Cl}$. Their study indicated that a small amount of binaural improvement may be considered significant for children with a $\mathrm{Cl}$.

Difference of opinions exist, however, regarding the use of the hearing aid in the non-implanted ear, in both the pediatric and adult $\mathrm{Cl}$ populations. Some recommend that hearing aids be discontinued, and following fitting with the $\mathrm{Cl}$, turn the focus on having the $\mathrm{Cl}$ user learn to listen with the implant alone (N. Gentile, personal communication, February 25, 1997; K. Sullivan, personal communication, February 18, 1997). Other clinics take a more cautious approach and recommend use of a hearing aid in the nonimplanted ear only if deemed beneficial to the individual (K. Schatz, personal communication, March 13, 1997).

Since the FDA approved the fitting of children with Cls, many studies have examined the auditory perception abilities of children with implants. Auditory perception implies an understanding and comprehension of acoustic stimuli, and testing of this ability assesses changes in auditory comprehension. Auditory perception test results have also been used to draw conclusions about the effects of Cls on children's auditory perception. If children who receive Cls show better auditory perception abilities as a function of binaural amplification, then this information needs to be considered when planning an intervention program for children. To further 
enhance the auditory abilities of $\mathrm{Cl}$ patients, the use of a hearing aid in the non-implanted ear is often suggested despite the little benefit that may exist when both devices are worn (Chute, Gravel, \& Popp, 1994). Chute et al. (1994) also noted that $\mathrm{Cl}$ users sometimes report a beneficial qualitative change in sound such as localization, detection, aid in balance, and more low frequencies detected while using the hearing aid in the contralateral ear. There appears, however, to be limited research to support or refute the continued use of amplification in the non-implanted ear for children with a cochlear implant.

\section{Statement of Purpose}

The primary purpose of this study was to determine whether children with Cls benefit from wearing a hearing aid in the non-implanted ear. Specifically, this study examined if performance on auditory perception tasks improves significantly using $\mathrm{Cls}$ and a conventional hearing aid in the nonimplanted ear compared with the use of a $\mathrm{Cl}$ alone. The corresponding hypothesis is that there is a clinically significant improvement in auditory perception abilities for children with Cls and a hearing aid in the nonimplanted ear over use of a $\mathrm{Cl}$ alone. The secondary purpose was to determine if the duration of use of a $\mathrm{Cl}$ with a hearing aid in the nonimplanted ear significantly affects auditory perception results. The corresponding hypothesis is that there is a clinically significant improvement 
in auditory perception abilities for children with a longer duration of use of a $\mathrm{Cl}$ with the use of a hearing aid in the non-implanted ear. 


\section{CHAPTER 2 \\ REVIEW OF LITERATURE}

Auditory Perception/Hearing Impaired Children

Auditory perception is a child's ability to understand speech through listening alone and is inferred based on the child's responses (Robbins \& Krik, 1996). Auditory perception also implies an understanding and comprehension of acoustic stimuli (Osberger et al., 1991).

Boothroyd (1985) showed that auditory perceptual abilities will be negatively impacted with increasing hearing impairment. Chmiel et al. (1995) observed that ability of the auditory system to process speech diminishes when the ear is deprived of adequate sound stimulation. Adequate auditory stimulation is critical for early developmental periods and school years for the child who is hearing impaired. This auditory stimulation will lessen the effects of auditory deprivation for the child who is hearing impaired. Northern and Downs (1991) noted that for children to accurately develop communication strategies, they need to hear acutely.

The optimal periods for auditory development is typically from 5 months of gestation to about 18 to 28 months after birth. (Northern \& Downs, 1991) Auditory skills begin to develop when the inner ear is completely formed and occurs at around 5 months of gestation. Northern and Downs 
(1991) also stated that during this developmental phase, auditory recognition partially depends on acoustic signals and partially on the listener's language ability.

The optimal period should be considered the time when the auditory behaviors are developed most easily. Studies examining auditory deprivation found that when an ear is deprived of adequate acoustic stimulation, the auditory system's ability to transmit speech to the ear decreases (Gantz, Tyler, Woodworth, Tye-Murray \& Fryauf-Bertschy, 1994). This impedes the language development process. Infants, both normally hearing and hearing impaired, cry and coo during the first few months of life and eventually begin to babble. Between the sixth and eighth months of life, infants with normal hearing begin to do variegated babbling which leads to words and, ultimately, to connected speech. The babbling rate of the child who is hearing impaired decreases with age while the auditory system continues to be under stimulated. This auditory isolation lessens the development of auditory behaviors that are needed to learn the oral language skills of adults. For children with hearing impairments, this can lead to academic and language learning difficulties.

$$
\text { Use of a Hearing Aid }
$$

Given this theory of deprivation, audiologists typically recommend binaural stimulation with conventional hearing aids for hearing impaired 
children. Chmiel et al's. (1995) study concluded that even minimal stimulation from hearing aids may be important in preserving hearing function for children. This may to lead to improved speech production and language usage. Numerous reports of children older than 28 months indicate that they have developed oral language skills once a hearing loss is diagnosed and some type of amplification system used (Northern \& Downs, 1991).

Some advantages noted from the use of binaural amplification are: elimination of the head shadow effect, auditory localization, and binaural summation. Elimination of the head shadow is one primary benefit experienced while using binaural amplification. It refers to the ability of the head to cast a sound shadow for those frequencies with wavelengths less than the actual dimensions of the head (Mueller \& Hawkins, 1990). When the head is between the receiving ear and the signal source, the intensity of the signal will be reduced as it passes around the head. This is most noted in the mid- and high-frequency sounds and typically begins at about $1500 \mathrm{~Hz}$. Attenuation of sound is noted up to about $15 \mathrm{~dB}$ at $5000 \mathrm{~Hz}$ (Mueller \& Hawkins 1990).

Auditory localization allows a listener to use two ears to aid in location of sound in space. Cues for auditory localization include interaural phase differences of the low frequencies (below $1500 \mathrm{~Hz}$ ), and intensity differences 
of the higher frequencies which help to produce a difference in the arrival of sound to the two ears. This difference allows one to interpret the location of the auditory signal in space. Binaural summation refers to the improvement in hearing sensitivity and increased loudness perception due to binaural stimulation. Monaurally, high frequency components will be attenuated 10 to $15 \mathrm{~dB}$ or more before the sound will reach the other ear.

A study by Gelfand and Silman (1993) examined auditory recognition abilities of monaurally and binaurally aided subjects. For those aided binaurally subjects' scores remained stable for both ears while unaided scores for those aided monaurally showed a significant reduction. Studies have also found that there is considerable variation in aided auditory perception performance of profoundly hearing impaired children, especially for those responding between 90 and $110 \mathrm{~dB} \mathrm{HL}$ (Geers, 1994).

Auditory perception test results have also been used to draw conclusions about the effects of Cls and children's auditory perception. If children who receive Cls show better auditory perception abilities as a function of binaural amplification, then this information needs to be considered when planning an intervention program for children. A study by Chmiel et al. (1995) asked whether a hearing aid would enhance auditory perception abilities or provide conflicting acoustical signals that make it difficult to integrate electrical signals with a $\mathrm{Cl}$. Their research showed some 
children with a $\mathrm{Cl}$ did benefit from a hearing aid in the non-implanted ear, and the small binaural improvement may have been considered significant. They attributed their findings to the severity of the children's hearing loss and the fact that these children received minimal benefit from a conventional hearing aid prior to the implantation.

\section{The Cochlear Implant}

The components of the cochlear implant work together to provide an increased detection of sound for individuals who are profoundly hearing impaired. Sound is first received by a microphone and then sent to a speech processor. The speech processor selects and codes auditory information and transmits it to a transmitter. The transmitter sends code across the skin to a receiver or microelectronic processor (which acts as a receiver/stimulator) (Tyler, 1993). This receiver converts the sound into electrical signals and sends the signals to the electrode array which in turn stimulates the nerve fibers.

The electrical stimulation occurs within the inner ear (the cochlea) and relies on the auditory nerve fibers that remain viable in individuals with sensorineural deafness (Northern \& Downs, 1991). These nerve fibers remain intact so direct electrical stimulation of certain strength and duration can send nerve impulses to the auditory nerve and then on to the auditory cortex much like normal neural impulses are routed to the auditory cortex. 
This electrical stimulation allows the brain to interpret the neural impulses as sound.

A commonly used $\mathrm{Cl}$ is the Nucleus 22 cochlear implant. The Nucleus 22 is a multichannel intra-cochlear implant with an electrode array of 22 bands. Two speech processors have recently been used with this system: the Mini Speech Processor (MSP) and the Spectra 22. The speech processor is designed to provide a coding strategy for the incoming speech signal (Nevine \& Chute, 1996). The coding strategy conveys information of pitch, loudness, and timing of the acoustic input signal as an electrical signal for the receiver to send to the electrode array in the cochlea. The processor will extract and encode the acoustic signals picked up by the microphone and encode it into electric current (Staller, Beiter, \& Birmacombe, 1994).

The MSP processor was designed to identify four different parts of the speech signal or speech features and assign each part to a different electrode. The Spectra 22 was designed to identify the size of the most prominent peaks of the incoming signal and present the information to the electrode that corresponds to the frequency content of the signal (Nevine \& Chute, 1996). This also enhances the redundancy of the speech information sent to the electrodes.

Each implant recipient's processor can digitally adjust the current according to their threshold levels $(T)$ and maximum comfort levels $(C)$. The 
T level is the level where the individual will first identify a sound sensation and where it is heard every time it is presented (Tyler, 1993). The C level is the maximum level at which a series of pulses is heard that does not produce an uncomfortable loudness sensation for the individual (Tyler, 1993). The stimulus mode programmed for each $\mathrm{Cl}$ user then controls how much of the electrode array stimulation will occur each time.

\section{Cochlear Implant Auditory Perception}

Auditory perception test results have been used to draw conclusions about the effects a cochlear implant has on children's auditory perception abilities. These auditory perception abilities of cochlear implant users are continually being examined because improvements to the implant processing device are ongoing. One study looking at prelingually deafened children found who they performed similarly on auditory perception tests to children that had normal hearing at birth and lost their hearing by 3 years of age (Miyamoto, Osberger, Robbins, Myres, \& Kessler, 1993). Children deafened, after 5 years of age, adjust to using a $\mathrm{Cl}$ in less time and with better results than prelingually deafened children (Miyamoto et al., 1993). A study by Staller et al. (1994) found that those children who received Cls prior to 6 years of age showed greater improvements in auditory perception abilities than older children. 
An age factor appears to play a role in auditory perception performance. A study by Miyamoto, Kirk, Todd, Robbins, and Osberger (1994) observed significant auditory perception benefits for children who are prelingually profoundly deafened using a multichannel cochlear implant. They noted that the longer the duration of device use, the more significant improvement on open and closed speech perception tests. Studies have also compared auditory perception performance abilities of cochlear implant children with that of children who use conventional hearing aids and found that, when they were matched by age, initial cochlear implant scores were below the hearing aid children's scores (Miyamoto et al., 1994). However, after about 2.5 years of cochlear implant usage, the scores for the cochlear implant group exceeded the hearing aid group (Miyamoto et al., 1994). Vermuelen, Buek, Broks, VanDen Borne, and VanDen Broek (1994) found that auditory perception skills of children in the cochlear implant group were significantly better than the children in the hearing aid group with comparable losses.

\section{Candidacy}

The FDA first approved the $\mathrm{Cl}$ for adults in 1984. Clinical trials with the House Single-Channel $\mathrm{Cl}$ for children began in 1980 with approval coming in 1985 for children age 2 and older (Tyler, 1993). For the pediatric population, determining who is an appropriate candidate for a $\mathrm{Cl}$ is 
challenging because of the difficulties in measuring the benefits of amplification in young children. It is for this reason that the potential for success with a Cl must be carefully evaluated for each child. In 1990, the FDA approval for the Nucleus Multi-Channel $\mathrm{Cl}$ for implanting prelingually deaf children stated that only those with bilateral hearing losses above $90 \mathrm{~dB}$ HL should be eligible candidates for surgery (National Institute of Health, 1995). A minimum of 2 years of age was determined to help establish the diagnosis of deafness with full audiological information and hearing aid performance evaluation. The pre-evaluation procedures also assessed whether there were additional handicaps that may adversely affect the potential success with an implant and if there was strong evidence of family support. Table 1 lists a summary of the minimum criteria for implant candidacy.

Because not all individuals with such profound hearing losses will benefit from a $\mathrm{Cl}$, a candidate must complete a medical, psychological, and audiological assessment along with assessments by speech-language pathologists. For the pediatric patients and their families, there must be sufficient motivation to follow the aural rehabilitation process after the surgery. It is for this reason that a multidisciplinary team approach is recommended for $\mathrm{Cl}$ candidacy determination. The team will not only assist in determining candidacy for surgery but also perform the surgery, activate 
the implant system after the incision has healed, and help the patient receive the most benefit from the device.

The team should consist of at least an audiologist, surgeon, otologist, psychologist, speech-language pathologist, and the parents and teachers. The multidisciplinary team should support the concept of practical rehabilitative needs of the child after surgery, meaning that the child needs to be placed in an environment that accommodates the child's hearing loss.

Table 1

Candidacy Requirements for Cochlear Implants

Minimum criteria for implant candidacy (FDA approved):

- older than 24 months - 17 years

- profound sensorineural hearing loss in both ears

- little or no benefit from hearing aid or vibrotactile aids (other amplification)

- educational program that emphasizes auditory skills with trial period for learning where the child has failed/or sufficient learning has not been met

- family and child with high motivational and appropriate expectations

- no medical contraindications

(Northern, 1986)

\section{Binaural Amplification for $\mathrm{Cl}$ users}

Review of the literature indicates that adult $\mathrm{Cl}$ users have been encouraged to continue wearing a hearing aid in the non-implanted ear to enhance any auditory objective or subjective measures of benefit. These adults have indicated some benefit of sound quality, which was noted as a 
qualitative benefit (Chute et al., 1994). Binaural stimulation has proven beneficial to adult $\mathrm{Cl}$ users and hearing impaired children who use conventional hearing aids, but few studies have examined binaural stimulation for cochlear implant children. This is mainly due to one of the candidacy requirements for children with cochlear implants; that is, these children have demonstrated little or no benefit from pre-implant hearing aid usage and training.

Because auditory perception implies an understanding and comprehension of acoustic stimuli, some clinicians wonder whether a hearing aid would enhance auditory perception abilities or provide conflicting acoustical signals that make it difficult to integrate electric signals to these children (Chmiel et al., 1995). While hearing aids are effective, they may not work well for the children who are profoundly impaired, and because of the requirements for $\mathrm{Cl}$ candidacy, many clinics try to keep the hearing aid on the opposite ear and then gradually phase it out.

There are however several opinions regarding this practice. Some believe the child should try to listen only with the implant (K. Sullivan, personal communication, February 18, 1997). N. Gentile (personal communication, February 25, 1997) stated that in their clinic the practice of using a hearing aid with a $\mathrm{Cl}$ is not recommended due to the paucity of evidence that exists about how the different signals are integrated and 
wondered if the hearing aid would provide a conflicting signal to the $\mathrm{Cl}$ user. Others recommend that the hearing aid in the opposite ear should be used unless there is absolutely no hearing in the contralateral ear (K. Schatz, personal communication, March 13, 1997). Schatz continued to state that only after documentation showing that the hearing aid in the non-implanted ear adds nothing to the patient's performance (e.g., localization, detection, etc.), would it be acceptable to discontinue their simultaneous use. A professional from another clinic stated that their implantation criteria are strict enough that if a child was receiving useful information from a hearing aid, they would probably not be implanted (G. Clark, personal communication, March 10, 1997). Still another noted that in all cases where there was sufficient hearing that a hearing aid would make any difference, one would be used in their clinic (D. W. House, personal communication, May 11, 1997).

There appears, however, to be limited research to support or refute the use of amplification in the non-implanted ear for these $\mathrm{Cl}$ children, and choosing treatment approaches is difficult for clinicians without adequate research. Because of the lack of guidelines regarding binaural stimulation with $\mathrm{Cl}$, users some clinics choose to recommend removal of a contralateral hearing aid. Still other clinics suggest continued use unless there is evidence that the hearing aid in the non-implanted ear offers no additional benefit. Those children who continue to wear a hearing aid along with a 
cochlear implant need to be tested to determine if a significant benefit to their auditory production abilities occurs. Examining binaural stimulation of $\mathrm{Cl}$ users with a hearing aid in the contralateral ear, information regarding what each ear is processing may be obtained.

The focus of this study was to compare binaural auditory stimulation benefits for children with a $\mathrm{Cl}$ and a hearing aid in the non-implanted ear with those children who use an implant alone. This will be accomplished by analyzing auditory perception test results. A group statistical design will incorporate an analysis of variance and regression analysis to determine if a significant difference exists between the $\mathrm{Cl}$ groups. 


\section{CHAPTER 3}

\section{METHOD}

This study attempted to determined whether children with a $\mathrm{Cl}$ benefit from wearing a hearing aid in the contralateral ear. Specifically, performance on different auditory perceptual listening situations tasks were compared between children using a $\mathrm{Cl}$ + hearing aid (Group 2) versus those using a $\mathrm{Cl}$ only (Group 1). A group statistical design was employed to determine if a difference in auditory perception test results existed between groups.

\section{Subjects}

The subjects of this study were 14 children enrolled in an auditory-oral training program who have a cochlear implant. Eight of these children also wear a hearing aid in the non-implanted ear. All children are enrolled at Tucker Maxon Oral School in Portland, Oregon. The age range for these children was $6: 7$ to $17: 10$ and the age of initial implant ranged from $1: 5$ to 10:7. One ear of each child was fit with the Nucleus 22 channel cochlear implant. For those students utilizing amplification in the contralateral ear, a behind-the-ear hearing aid was used (see Table 2) 
Table 2

Subject Profile

\begin{tabular}{|c|c|c|c|c|c|c|c|}
\hline Subject & ${ }^{\star}$ Age & $\begin{array}{l}\text { Age at } \\
\text { Surgery }\end{array}$ & $\begin{array}{l}\text { Number of } \\
\text { Electrodes }\end{array}$ & $\begin{array}{c}\text { Ear } \\
\text { Implanted }\end{array}$ & $\begin{array}{l}\text { Hearing Aid } \\
\text { Used }\end{array}$ & Etiology & $\begin{array}{l}\text { Educational } \\
\text { setting }\end{array}$ \\
\hline 1 & $12: 11$ & $7: 3$ & 20 & $R$ & $\begin{array}{l}\text { last used } \\
\text { in } 1993\end{array}$ & $\mathrm{C} / \mathrm{U}$ & TC/Oral \\
\hline 2 & $16: 5$ & $5: 9$ & 20 & $\mathrm{R}$ & none & $\mathrm{C} / \mathrm{H}$ & Oral \\
\hline 3 & $12: 2$ & $8: 7$ & 9 & $L$ & none & $\begin{array}{l}\text { Meningitis } \\
\text { (12 mon) }\end{array}$ & TC/Oral \\
\hline 4 & $10: 3$ & $6: 5$ & 20 & $R$ & none & Ushers & Oral \\
\hline 5 & $11: 7$ & $7: 7$ & 20 & $L$ & none & $\begin{array}{l}\text { Meningitis } \\
\text { (12 mon) }\end{array}$ & Oral \\
\hline 6 & 13:2 & $4: 10$ & 20 & $L$ & none & Meningitis & TC/Oral \\
\hline 7 & $9: 7$ & $4: 10$ & 19 & $R$ & $\begin{array}{c}\text { Phonak Audinet } \\
\text { PPCL }\end{array}$ & $\begin{array}{l}\text { C/PCF } \\
\text { (blind) }\end{array}$ & Oral \\
\hline 8 & $10: 8$ & $5: 10$ & 20 & $\mathrm{R}$ & $\begin{array}{c}\text { Phonak Audinet } \\
\text { PPCL }\end{array}$ & $\begin{array}{l}\text { C/LVAS } \\
\text { progressive }\end{array}$ & Oral \\
\hline 9 & $17: 11$ & $5: 10$ & 20 & $L$ & Oticon E38P & $\mathrm{C} / \mathrm{U}$ & Oral \\
\hline 10 & $7: 10$ & $1: 7$ & 20 & $L$ & $\begin{array}{l}\text { Phonak Audinet } \\
\text { PPCL }\end{array}$ & $\mathrm{C} / \mathrm{U}$ & Oral \\
\hline 11 & $9: 11$ & $3: 8$ & 20 & $\mathrm{R}$ & Unitron E1P & $\mathrm{C} / \mathrm{U}$ & Oral \\
\hline 12 & $9: 0$ & $3: 3$ & 20 & $R$ & $\begin{array}{l}\text { Phonak Audinet } \\
\text { PPCL }\end{array}$ & $\mathrm{C} / \mathrm{H}$ & Oral \\
\hline 13 & $10: 5$ & $6: 1$ & 20 & $L$ & $\begin{array}{c}\text { Phonak Audinet } \\
\text { PPCL }\end{array}$ & CMV & Oral \\
\hline 14 & $6: 8$ & $2: 9$ & 20 & $L$ & Phonak Picoforte & $\mathrm{C} / \mathrm{U}$ & Oral \\
\hline
\end{tabular}


Instruments

There are a number of tests that are available to determine the auditory abilities of children with hearing impairments. This study used the Early Speech Perception Test (ESP) (Geers \& Moog, 1990). This test was based on research reported by Erber (1982). The ESP, a closed-set auditory perception test, was designed for use with children with limited vocabulary. Open-set auditory perception tests incorporate no choice of response when testing and may be a better representation of the real-world performance of a child who is hearing impaired. Closed-set auditory perception tests incorporate a choice of response alternatives, which typically are in a multiple picture format. This choice of test is influenced by the number and similarity of foils that may make it easier for a child (i.e., involving less memory).

There are two versions of the ESP: the Low Verbal Version and the Standard Version. The Standard Version has three subtests: (1) the pattern perception test which contains the standard pattern/perception and word identification tests; (2) the spondee identification test, which is a closed set of 12 spondees; and (3) the monosyllabic identification test, which uses 12 monosyllables starting with the sound /b/ (Erber, 1982). The Low Verbal Version is designed for use with a child who is at a low or limited vocabulary level. The Low Verbal version also has three subtests that are parallel to the 
standard version, but use toys instead of pictures for the identification task. Overall test results are used to rank a child into four auditory perception categories: (1) no pattern perception; (2) pattern perception; (3) some word identification, and (4) consistent word identification (Erber, 1982). Because of the developmental level of the subjects in this study, the standard version of the ESP test was used.

Category one (i.e., no pattern perception) is used to identify a child who cannot detect amplified speech or a child who can detect auditory input, but has not developed an ability to discriminate between the different speech patterns. Category two (i.e., pattern perception) identifies a child who has developed a minimal level of skills to perceive speech, ranging from a level of discriminating between words and phrases with different durational patterns to identifying different units with different stress patterns such as cookie and airplane. This level shows that the child is beginning to use spectral information to discriminate between vowels or consonants sounds. Category three (i.e., some word identification) identifies a child's ability to use the spectral or intonation information in the auditory signal. At this level, discrimination between words and phrases with similar stress and duration patterns (cowboy vs. bathtub) is reached and is demonstrated by how well the child can differentiate between the different vowels. Finally, category four (i.e., consistent word identification) identifies the child's increased ability to 
perform discrimination between spectral information. Here a child demonstrates the ability to discern between single-syllable words with different vowel sounds, especially in large closed sets (e.g., 12 choices on the ESP).

The ESP was used to measure the effects of auditory training and the effectiveness of the device used. The test provides a measurement of the ability to perceive auditory information for a child and indicates information regarding the integration of auditory perception between the $\mathrm{Cl}$ and the hearing aid test situations (Geers \& Moog, 1990). The subtests can be administered in an auditory/visual mode to insure that vocabulary will be familiar to the child. Once it is established that the child comprehends all of the words in a subtest, the subtest can then be administered auditory only. For this study, an auditory only approach was used.

The pattern perception subtest uses the word categorization subtest of the Glendonald Auditory Screening Procedure (GASP) (Erber, 1982) to measure the ability to recognize temporal patterns in speech. This subtest uses 12 different words with four types of duration or stress patterns: monosyllable (e.g., shoe), trochee (e.g., cookie), spondee (e.g., airplane), and three-syllable words (e.g., hamburger) on a picture board. The test items are administered using visual and listening clues such as lipreading and signing to ensure the child can easily identify the item, then the ability to 
identify the item through listening alone is assessed. For the standard pattern/perception test, a word is considered correct if a word with the same stress pattern is chosen (e.g., airplane for hotdog). For the word identification test, a word is considered correct if a word is chosen out of a choice of words with different stress patterns ( e.g., cookie and airplane). If 17 out of 24 are recorded correct on each of the pattern perception subtests, the child advances to category 2 and the spondee test can then be administered.

The spondee identification test examines the ability to perceive durational patterns in the acoustic signal. Twelve spondees with different vowels and consonants are used in this test (e.g., bathtub, popcorn). As with the pattern perception test, the spondee identification task confirms successful audiovisual performance before an auditory only presentation is assessed (Erber, 1982). The spondee identification subtest requires the child to point to a picture representing the word spoken. If a child obtains 8 out of 24 correct on the spondee identification subtest the child advances to category 3 and the monosyllable identification subtest, can be administered.

The monosyllable identification subtest provides a more difficult test of word recognition for those who show recognition skills on the spondee subtest (Erber, 1982). This subtest incorporates 12 words that begin with the /b/ sound and end with a plosive consonant (e.g., bed, boat). The task 
requires identification of test items by pointing to a picture and using vowel recognition skills. If a score of at least 13 out of 24 is obtained on this monosyllable identification task the auditory perception category 4 will be recorded. Attainment of category 4 on the ESP indicates the child demonstrated good auditory discrimination. Once this category on the ESP has been achieved, further testing should be continued with other standard auditory perception and discrimination measures investigating higher level auditory skills.

\section{Procedures}

The subjects were tested by a state licensed ASHA certified Educational Audiologist or the principal investigator working under the Audiologist's supervision. The subjects were seated comfortably in a chair, with their back to the audiologist. Their ears were examined to ensure the canals were free of cerumen.

Each amplification device used by each subject was checked before testing began to ensure that it was functioning properly. A subjective listening task, at a normal conversational level (70 dB SPL), was performed to verify normal function of the cochlear implant. For the older children, the tester asked "is your implant working?" The younger children were given the Ling 5 sound test to assess the function of their $\mathrm{Cl}$. The tester verbalizes sounds one at a time, without visual cues, and the child repeats the sound or 
otherwise indicates he or she heard it. (Ling, 1989) Hearing aids were examined electroacoustically. Batteries for both the $\mathrm{Cl}$ and the hearing aid devices were also checked.

The ESP was administered using live voice (LV) by the audiologist. Presentation of test items using LV is used by the audiologist at Tucker Maxon Oral School to maintain strict acoustic control between testing dates. Because the ESP is not a test that assesses threshold (Erber, 1982) live voice was chosen to assure listening levels were at a comfortable level. Given that the profoundly deaf individual's hearing capabilities are minimal, using live voice allows more control over the test situation. Using recorded stimuli with profoundly impaired children creates difficulty in determining when the child is ready to listen and the pace of stimuli presentation. Across the different subtests of the ESP, the test stimuli were presented in random order to assure no item was presented more than twice in succession.

The raw scores on each subtest were used in a group statistical design. Regression analysis was used to determine if the addition of a conventional hearing aid in the contralateral ear of $\mathrm{Cl}$ users made a significant contribution to the performance on the ESP speech perception test. Regression analysis was also used to determine if duration of $\mathrm{Cl}$ use had a significant impact on subtest scores of the ESP test. Because of the differential pattern of performance across the subtests, a repeated measure 
analysis of variance and Tukey's pairwise comparison was also conducted to determine if a difference existed across the subtests of the ESP within the two groups. Each statistical analysis score was evaluated at an $\alpha$ level of .05 . 


\section{CHAPTER 4 \\ RESULTS AND DISCUSSION}

The purpose of this study was to investigate binaural auditory stimulation benefits for children with a cochlear implant and a hearing aid in the non-implanted ear. Specifically the first hypothesis examined if performance on auditory perception tasks improved using $\mathrm{Cls}$ and a conventional hearing aid in the non-implanted ear compared with the use of a $\mathrm{Cl}$ alone. The second hypothesis investigated auditory perception results to determine if using a $\mathrm{Cl}$ and a hearing aid in the contralateral ear improved as a function of length of use.

Table 3 displays the subject's age in months and the duration of cochlear implant usage in months at the time of testing for each subject. The mean age for Group 1 ( $\mathrm{Cl}$ only) was 12 years, 9 months and the mean duration of $\mathrm{Cl}$ use was 6 years, 9 months. The mean age for Group $2(\mathrm{Cl}+$ hearing aid) was 10 years, 4 months and the mean duration of $\mathrm{Cl}$ use was 4 years, 3 months.

Table 4 reports the relationship between the duration of $\mathrm{Cl}$ use and the subjects' performance on the ESP subtests. The results of the regression analysis revealed that duration of $\mathrm{Cl}$ use did not significantly impact on subtest scores of the ESP test between either groups. Because of this 
finding, duration of cochlear implant usage was eliminated as a variable in the data analysis process.

Table 3

Group age, duration, mean

\begin{tabular}{|c|c|c|}
\hline Subject & $\begin{array}{c}\text { Age at test } \\
\text { date }\end{array}$ & $\begin{array}{l}\text { Duration } \\
\text { of } \mathrm{Cl} \text { use }\end{array}$ \\
\hline \multicolumn{3}{|c|}{ Group 1 (Cl only) } \\
\hline 1 & $12: 11$ & $7: 3$ \\
\hline 2 & $16: 5$ & $5: 9$ \\
\hline 3 & $12: 2$ & $8: 7$ \\
\hline 4 & $10: 3$ & $6: 5$ \\
\hline 5 & $11: 7$ & $7: 7$ \\
\hline 6 & $13: 2$ & $4: 10$ \\
\hline Mean & $12: 9$ & $6: 9$ \\
\hline \multicolumn{3}{|c|}{ Group $2(\mathrm{Cl}+$ Hearing Aid $)$} \\
\hline 7 & $9: 7$ & $4: 9$ \\
\hline 8 & $10: 8$ & $5: 10$ \\
\hline 9 & $7: 11$ & $5: 10$ \\
\hline 10 & $7: 10$ & $1: 7$ \\
\hline 11 & $9: 11$ & $3: 8$ \\
\hline 12 & $9: 0$ & $3: 3$ \\
\hline 13 & $10: 5$ & $6: 11$ \\
\hline 14 & $6: 8$ & $2: 9$ \\
\hline Mean & $10: 3$ & $4: 3$ \\
\hline
\end{tabular}


Table 4.

Regression Analysis

Relationship of Duration of Implant Usage and Subtest between Groups

\begin{tabular}{lllll}
\hline Subtest & $\begin{array}{l}\text { Coefficient of } \\
\text { Regression }\end{array}$ & SD & T-ratio & P \\
\hline $\begin{array}{l}\text { Standard } \\
\text { Pattern/Perception }\end{array}$ & .0098 & .0292 & .34 & .744 \\
\hline Word Id & .0219 & .0056 & .39 & .703 \\
\hline Spondee Id & .0158 & .0763 & .21 & .840 \\
\hline Monosyllable Id & .0510 & .0796 & .64 & .536 \\
\hline
\end{tabular}

Note: SD $=$ Standard Deviation

Performance data on the ESP subtests from Group 1 and overall scores achieved on the ESP subtests are displayed in Table 5. The standard/pattern perception test scores ranged from 15-24 correct, with a mean score of 21.50 and a standard deviation of 3.51. Scores obtained on the word identification test had a range of scores between $8-24$, a mean score of 20.17 , and a standard deviation of 6.21 . Scores obtained on the spondee identification test had a range of scores between $5-24$, a mean of 16.50 and a standard deviation of 8.85 ; and the scores obtained on the monosyllable identification test ranged from 3-24, with a mean of 17.67 and a standard deviation of 7.55 . 
Performance data on the ESP subtests from Group 2 and overall scores achieved on the ESP subtests are presented in Table 6. The standard/pattern perception test scores ranged from 23-24 correct with a mean score of 23.88 and a standard deviation of 0.35 . Scores on the word identification test had a range of scores from 23-24, a mean of 23.63, and a standard deviation of 0.74 . Scores on the spondee identification test had a range of 23-24, a mean of 23.75 and a standard deviation of 0.46 ; and scores for the monosyllable test had a range of $15-24$, a mean of 21.63 , and a standard deviation of 2.97 .

Regression analysis was used to test the first research hypothesis in order to determine group differences and to identify if the addition of a conventional hearing aid in the contralateral ear of $\mathrm{Cl}$ users made a significant contribution to the performance on the ESP speech perception test. Tables 7 and 8 display analyses of the standard pattern/perception and word identification tests and indicate scores between the groups were significantly different at the .05 level $(P=.034$ and $P=.046$ respectively). However, the spondee identification and monosyllable identification tests (Tables 9 and 10$)$ were not significant at the .05 level $(P=.073$ and $P=.079$, respectively). The difference that was noted between the $\mathrm{Cl}+$ hearing aid and $\mathrm{Cl}$ only groups on the standard pattern/perception and the word 
Table 5

Data of ESP Subtests for Group 1 (Cl only)

\begin{tabular}{cccccc}
\hline Subject & Age & $\begin{array}{c}\text { Standard } \\
\text { Pattern/ } \\
\text { Perception }\end{array}$ & $\begin{array}{c}\text { Correct responses } \\
\text { Word Id }\end{array}$ & $\begin{array}{c}\text { Spondee } \\
\text { Id }\end{array}$ & $\begin{array}{c}\text { Monosyllable } \\
\text { Id }\end{array}$ \\
\hline 1 & $12: 11$ & 24 & 24 & 24 & 23 \\
2 & $16: 5$ & 21 & 20 & 12 & 14 \\
3 & $12: 2$ & 15 & 8 & 3 & 5 \\
4 & $10: 3$ & 24 & 24 & 24 & 24 \\
5 & $11: 7$ & 21 & 21 & 12 & 16 \\
6 & $13: 2$ & 24 & 24 & 24 & 24 \\
\hline & Range & $15-24$ & $8-24$ & $3-24$ & $5-24$ \\
& Mean & 21.50 & 20.17 & 16.50 & 17.67 \\
& Stdev & 3.51 & 6.21 & 8.85 & 7.55 \\
\hline
\end{tabular}

Table 6

Data of ESP Subtests for Group $2(\mathrm{Cl}+$ Hearing aid $)$

\begin{tabular}{|c|c|c|c|c|c|}
\hline \multirow[b]{2}{*}{ Subject } & \multirow[b]{2}{*}{ Age } & \multicolumn{4}{|c|}{ \# correct responses } \\
\hline & & $\begin{array}{c}\text { Standard } \\
\text { Pattern/ } \\
\text { Perception }\end{array}$ & Word Id & $\begin{array}{c}\text { Spondee } \\
\text { Id }\end{array}$ & $\begin{array}{c}\text { Monosyllable } \\
\text { Id }\end{array}$ \\
\hline 7 & $9: 7$ & 24 & 24 & 24 & 24 \\
\hline 8 & $10: 8$ & 24 & 24 & 24 & 24 \\
\hline 9 & $17: 11$ & 24 & 22 & 23 & 15 \\
\hline 10 & $7: 10$ & 23 & 23 & 23 & 22 \\
\hline 11 & $9: 11$ & 24 & 24 & 24 & 21 \\
\hline 12 & 9:0 & 24 & 24 & 24 & 22 \\
\hline 13 & $10: 5$ & 24 & 24 & 24 & 24 \\
\hline \multirow[t]{4}{*}{14} & $6: 8$ & 24 & 24 & 24 & 21 \\
\hline & Range & $23-24$ & $23-24$ & $23-24$ & $15-24$ \\
\hline & Mean & 23.88 & 23.63 & 23.75 & 21.63 \\
\hline & Stdev & 0.35 & 0.74 & 0.46 & 2.97 \\
\hline
\end{tabular}


Table 7

Regression Analysis for the ESP Standard Pattern/Perception test

\begin{tabular}{lllll}
\hline Predictor & Coefficient & Stand Dev & T-ratio & $\mathrm{P}$ \\
\hline Constant & 23.88 & 0.54 & 44.45 & 0.00 \\
Group & 4.73 & 1.95 & 2.42 & 0.034 \\
interact & -0.10 & 0.02 & -4.00 & 0.002 \\
\hline
\end{tabular}

Table 8

Regression Analysis for the ESP Word Identification test

\begin{tabular}{lclcl}
\hline Predictor & Coefficient & Stand Dev & T-ratio & $P$ \\
\hline Constant & 23.63 & 1.03 & 22.97 & 0.00 \\
Group & 8.43 & 3.74 & 2.25 & 0.046 \\
interact & -0.16 & 0.05 & -3.5 & 0.005 \\
\hline
\end{tabular}

Table 9

Regression Analysis for the ESP Spondee Identification test

\begin{tabular}{lllll}
\hline Predictor & Coefficient & Stand Dev & T-ratio & $\mathrm{P}$ \\
\hline Constant & 23.75 & 1.40 & 16.97 & 0.00 \\
Group & 10.09 & 5.09 & 1.98 & 0.073 \\
interact & -0.24 & 0.06 & -3.75 & 0.003 \\
\hline
\end{tabular}

Table 10

Regression Analysis for the ESP Monosyllable Identification test

\begin{tabular}{lllll}
\hline Predictor & Coefficient & Stand Dev & T-ratio & $\mathrm{P}$ \\
\hline Constant & 21.63 & 1.49 & 14.55 & 0.00 \\
Group & 10.47 & 5.41 & 1.94 & 0.079 \\
interact & -0.20 & 0.07 & -2.94 & 0.013 \\
\hline
\end{tabular}


identification tests could have been influenced by the low level of processing skills required to complete the tasks.

A simple detection of auditory signals (standard pattern/perception) and the ability to discern between words and phrases by identifying durational and stress patterns (word identification) could have been enhanced for Group 2 by the additional use of a hearing aid. A lack of difference between groups, however, was expected between the spondee identification and the monosyllable identification tests which requires processing of higher level tasks. Interpreting these results is somewhat difficult. Differences were noted for the lower level tasks and, as stated, this was expected. However, the failure to document a statistical difference on the higher level tasks was probably due to the wider variance in the performance of Group 1 as Group 2 maintained a higher average between groups on both the spondee identification and the monosyllable identification tests. Since differences were noted only for the standard pattern/perception and word identification tests, suggesting a differential pattern of performance across the subtests, it was decided to investigate differences across the subtests within each group.

A repeated measure analysis of variance and Tukey's pairwise comparison was also conducted to determine if a difference existed across the subtests of the ESP within the two groups. The results of the repeated 
measure analysis of variance tests, shown in Tables 11 and 12, revealed a significant difference existed across the four tests for each of the two groups, but it was not evident where the difference occurred. A post-hoc analysis using Tukey's pairwise comparisons (Tables 13 and 14) for each individual group showed differences existed between the monosyllable identification and word identification tests, the monosyllable identification and spondee identification tests, and the monosyllable and standard pattern/perception tests for Group 1 and the spondee identification and word identification tests, the spondee identification and standard pattern/perception tests, the monosyllable identification and word identification test and the monosyllable identification and standard pattern/perception tests for Group 2. This difference between the tests is consistent with the hierarchical setup of tasks for each of the tests on the ESP. Considering the hierarchical arrangement of the ESP test, it was expected that, if a difference was going to be present, it would be noted between the spondee identification and the monosyllable identification tests. These two higher subtests of the ESP require an ability to discriminate between words and phrases with similar stress and duration patterns to an ability to discern between spectral information to aid in the ability to differentiate between single-syllable words with different vowel sounds. 
Table 11

Analysis of Variance Group 1 ( $\mathrm{Cl}$ only)

\begin{tabular}{lcrrrr}
\hline Source & DF & \multicolumn{1}{c}{ SS } & MS & F & P \\
\hline Subtest & 3 & 93.79 & 31.26 & 4.45 & 0.02 \\
Error & 15 & 105.46 & & & \\
Total & 23 & 1024.96 & & & \\
\hline
\end{tabular}

Table 12

Analysis of Variance Group $2(\mathrm{Cl}+$ Hearing aid)

\begin{tabular}{lccccc}
\hline Source & DF & SS & MS & F & P \\
\hline Subtest & 3 & 27.344 & 9.12 & 4.8 & 0.011 \\
Error & 21 & 39.906 & 1.9 & & \\
Total & 31 & 95.469 & & & \\
\hline
\end{tabular}


Table 13

Tukey's Pairwise Comparison Group 1 ( $\mathrm{Cl}$ only)

\begin{tabular}{lcccc}
\hline & $\begin{array}{c}\text { Monosyllable } \\
\text { Id }\end{array}$ & $\begin{array}{c}\text { Spondee } \\
\text { Id }\end{array}$ & Word Id & $\begin{array}{l}\text { Standard } \\
\text { Pattern/ } \\
\text { Perception }\end{array}$ \\
Test/mean & 24.62 & 23.62 & 23.75 & 23.87 \\
score & & $2.00^{\star}$ & $2.13^{\star}$ & $2.75^{\star}$ \\
\hline Monosyllable Id & & & .13 & .25 \\
Spondee Id & & & & .12 \\
Word Id & & & \\
Stan Pattern/ & & & \\
Perception & & & & \\
\hline${ }^{\star} \mathrm{p}<.05$ & & &
\end{tabular}

Table 14

Tukey's Pairwise Comparison Group $2(\mathrm{Cl}+$ Hearing aid $)$

\begin{tabular}{lcccl}
\hline & $\begin{array}{c}\text { Monosyllable } \\
\text { Id }\end{array}$ & $\begin{array}{c}\text { Spondee } \\
\text { Id }\end{array}$ & Word Id & $\begin{array}{l}\text { Standard } \\
\text { Pattern/ } \\
\text { Perception }\end{array}$ \\
Test/mean & 16.5 & 17.7 & 20.2 & 21.5 \\
score & & $1.20^{\star}$ & $3.70^{\star}$ & $5.00^{\star}$ \\
\hline Monosyllable Id & & & $2.50^{\star}$ & $3.80^{\star}$ \\
Spondee Id & & & & 1.30 \\
Word Id & & & \\
Stan Pattern/ & & & \\
Perception & & & & \\
\hline${ }^{*} p<.05$ & & &
\end{tabular}




\section{Discussion}

The standard pattern/perception test examined the ability to detect simple auditory input but not the ability to differentiate between speech patterns. The word identification test examined the ability to discriminate between words and phrases with different durational patterns to identifying different units with different stress patterns. The results suggest that, for these lowest level auditory tasks, children with a $\mathrm{Cl}$ who also use a hearing aid may receive more auditory input while they are learning to interpret auditory signals. A hearing aid in the non-implanted ear may be supplying more low frequency and high intensity cues that the $\mathrm{Cl}$ may not be providing. The hearing aid could also be supplying prosodic cues and other segmental or supra-segmental cues to enhance a $\mathrm{Cl}$ users ability to interpret auditory signals. There clearly needs to be more research in the area of how the two signals $(\mathrm{Cl}+$ hearing aid) may be integrated.

It was expected that due to the low level processing tasks of the standard pattern/perception and word identification tests, no difference between the groups would be noted and the difference would be seen with the higher level tasks of the spondee identification and monosyllable identification tests. Surprisingly, while there was a significant difference between the groups on the standard pattern/perception and word identification tests there was not a significant difference between the groups 
on the spondee identification and monosyllable identification tests. The spondee identification test assessed the ability to use the spectral or intonation information in the auditory signal by discriminating between words and phrases with similar stress and duration patterns. The monosyllable identification test assessed the ability to discriminate between spectral information. Cursory analysis of the results suggested that the two groups might have differed on these later two tests due to the difference in mean scores. However, the failure to demonstrate differences between the groups on these tests could have been influenced by the increased variance of the groups scores as compared with the standard pattern/perception and word identification tests. In particular, Group 1 showed considerably greater variance on these tests than did Group 2. The fact that these differences did not reach significance may have been influenced by the specifics of the task or the small sample size. 


\section{CHAPTER 5 \\ SUMMARY AND IMPLICATIONS}

The purpose of this study was to determine if those children who use a cochlear implant benefit on auditory perception tasks from the additional use of a hearing aid in the contralateral ear. This investigation also examined if the length of use of a cochlear implant effected auditory perception abilities. The method used to measure auditory perception was the Early Speech Perception test. Data were collected from 14 children, aged 6:7 to $17: 10$, who attend Tucker Maxon Oral School in Portland, Oregon. Six of the these students used a cochlear implant alone and 8 of the students used a cochlear implant along with a hearing aid in the contralateral ear.

It was hypothesized that (a) there would be a significant improvement on auditory perception test results between the group using a $\mathrm{Cl}$ and a hearing aid in the contralateral ear (Group 2), and the group using a $\mathrm{Cl}$ alone (Group 1) and that (b) there was a clinically significant improvement in auditory perception abilities for children with a longer duration of use of a $\mathrm{Cl}$ with a hearing aid in the contralateral ear. Duration of $\mathrm{Cl}$ use was found not to be statistically significant as a variable and removed from the analysis process. Scores on the standard pattern/perception and word identification tests were statistically different at the .05 level with the $\mathrm{Cl}+$ hearing aid 
group's performance exceeding that of the $\mathrm{Cl}$ only group. However, performance on the spondee identification and monosyllable identification tests did not significantly differ between the two groups. The results of this study, unfortunately, do not lead to conclusive results regarding whether a child with a $\mathrm{Cl}$ benefits from the additional use of a hearing aid in the nonimplanted ear, however, it does not refute the use of the hearing aid either.

The results demonstrate that Group 2 may have received some benefit from wearing a hearing aid in the opposite ear, at least as documented on the standard pattern/perception and word identification tests. The small improvement from binaural amplification noted could be considered significant, mainly because all of the subjects were profoundly hearing impaired and had little, if any, recorded benefit from initial trials with conventional hearing aids. However, these results were not expected based on the hierarchical set up of the ESP test. Surprisingly, while there was a significant difference between the groups on the standard pattern/perception and word identification tests there was not a significant difference between the groups on the spondee identification and monosyllable identification tests. Cursory analysis of the results suggested that the two groups might have differed on these later two tests due to the difference in mean scores. However, the failure to demonstrate differences between the groups on these tests could have been influenced by the increased variance of the groups 
scores as compared with the standard pattern/perception and word identification tests.

This lack of significant difference between the groups on the spondee identification and monosyllable identification tests also may have been caused by the fact that most of the scores obtained on the subtests of the ESP test by the individuals in each group showed a ceiling effect. In other words, the tasks did not appear to be sufficiently difficult to discriminate across the range of abilities these subjects demonstrated. Thus, the apparent ease of the task may have overridden the contribution of additional auditory stimulation provided by the hearing aids. An option for further research would be to consider a more controlled, longer term study that incorporates a different set of tests with higher level processing tasks. An additional option for further research would be to consider a task that incorporated a competing noise test. Examination of a competing noise task could lead to conclusions as to the benefit of auditory localization and how binaural summation could increase test performances.

Another factor that may have adversely affected results is the small subject number involved with the study. As with any research, smaller sample sizes will complicate the interpretation of results. However, since clinical trials with $\mathrm{Cl}$ in children age 2 and older only began in 1985 (Tyler, 1993), it is not unusual to have small subject samples. An option for further 
research would be to combine efforts with different clinics/schools and increase the subject number.

Currently, there are no set guidelines regarding the use of a hearing aid in the non-implanted ear for those who are fitted with a $\mathrm{Cl}$ and little is known about the integration of the implant signal and the signal from a hearing aid for a $\mathrm{Cl}$ user. Clearly, this area is in need of further exploration to educate clinicians and provide insight for future research. Future research could examine other binaural stimulation advantages such as increased auditory localization abilities, elimination of the head shadow effect, and binaural summation. Studies have indicated that even a small amount of binaural improvement may be significant for children fitted with a $\mathrm{Cl}$ (Chmiel et al., 1995). By adding a hearing aid to an aural rehabilitation plan of a $\mathrm{Cl}$ user it may lead to preventing auditory deprivation from occurring in the nonimplanted ear.

Although there is a lack of information on how the hearing aid and $\mathrm{Cl}$ signals are integrated, there was no evidence in this study that the hearing aid signal interferes with the $\mathrm{Cl}$ signal when they are used together. Regardless of the conflicting opinions that exist concerning the rehabilitative procedures for the $\mathrm{Cl}$ population, this study supports the use of both devices with no adverse effects on performance. At the very least, the option of using a hearing aid in the contralateral ear should not be discarded without 
evidence that indicates there is no benefit to the $\mathrm{Cl}$ recipient from a trial period with both devices.

\section{Summary}

The purpose of this investigation was to examine the benefits of binaural auditory stimulation for children with a cochlear implant and a hearing aid in the contralateral ear. The results of the current investigation revealed that the auditory perception performance of the $\mathrm{Cl}$ and $\mathrm{Cl}+$ hearing aid groups were similar and no significant difference was noted overall on the ESP test, although there was some significant differences in select subtests. If nothing else, these results indicate there definitely needs to be further research in this area. This study, however, supports the use of both devices with no adverse effects on performance. 


\section{REFERENCES}

Boothroyd, A. (1985). Auditory capacity and the generalization of speech skills. In J. Lauter, (Ed.), Speech planning and production in normal and hearing-impaired children. ASHA Reports, 15, 8-14.

Boothroyd, A., Geers, A. E., \& Moog, J. S. (1991). Practical Implication of Cochlear Implants in Children. Ear and Hearing, 12 (suppl 4), 81s-89s.

Chmiel, R., Clark, J. Jerger, J., Jenkins H., \& Freeman, R. (1995). Speech perception and production in children wearing a cochlear implant in one ear and a hearing aid in the opposite ear. Annals of Otology, Rhinology, \& Laryngology, 166 (suppl 5), 314-316.

Chute, P. M., Gravel, J. S., \& Popp, A. L. (1994). Speech perception abilities of adults using a multichannel cochlear implant and frequency transposition hearing aids., Annals of Otology, Rhinology, \& Laryngology, 166 (suppl 5), 260-263.

Erber, N. (1982). Auditory Training. Washington, DC: Alexander Graham Bell Association for the Deaf.

Gantz, B. J., Tyler, R. S., Woodworth, G. G., Tye-Murray, N., \& FryaufBertschy, H. (1994). Results of multi-channel cochlear implants and acquired prelingual deafness in children: five year follow-up. The American Journal of Otology, 15 (suppl 2), 1-7.

Geers, A. (1994). Techniques for assessing auditory speech perception and lipreading enhancement in young deaf children. Volta Review, 96, 85-96.

Geers, A. G., \& Moog, J. S. (1990). Early speech perception test battery. The Volta Review, 95 (5), 85-96.

Geers, A. G., \& Moog, J. S. (1994). Description of the CID sensory aids study. Volta Review, 96, 1-11.

Gelfand, S. A., \& Silman, S. (1993). Apparent auditory Deprivation in children: Implications of monaural versus binaural amplification. Journal of American Academy of Audiology, 4: 313-318. 
Ling, D. (1989). Foundations of spoken language for hearing-impaired children. Washington D.C.: AG Bell Association

Miyamoto, R. T., Kirk, K. I., Todd, S. L., Robbins, A. M., \& Osberger, M. J. (1994). Speech perception skills of children with multichannel cochlear implants or hearing aids. Annals of Otology, Rhinology, \& Laryngology, 166 (supple 5), 334-337.

Miyamoto, R. T., Osberger, M. J., Robbins, A. M., Myres, W. A., \& Kessler, K., (1993). American Journal of Otology, 14 (suppl 5), 437-445.

Mueller, H. G., \& Hawkins, J. E. (1990). Considerations in hearing aid selection. In R. Sandlin (Ed.) Handbook of hearing aid amplification, VIII: Clinical considerations and fitting practices (pp. 31-61). San Diego, College Hill Press,

National Institute of Health, (1995). Cochlear Implants in Adults and Children. NIH Consensus Statement On-line. May, 15-17 [Cited 1995, October 27]; 13(2):1-30.

Nevine, M. E., \& Chute, P. M. (1996). Children with cochlear implants in educational settings. San Diego, CA: Singular Publishing Group.

Northern, J. L. (1986). Selection of children for cochlear implantation, Seminars in Hearing, 7, 341-347.

Northern, J. L., \& Downs, M. (1991). Hearing in children (4th ed.). Baltimore, MD. Williams \& Wilkins.

Osberger, M. J., Miyamoto, R. T., Zimmerman-Phillips, S., Kemink, J. L., Stroer, B. S., Firszt, J. B. \& Novak, M. A. (1991). Independent evaluation of the speech perception abilities of children with the nucleus 22-channel cochlear implant system. Ear and Hearing, 12, suppl 4, s66 - s79.

Robbins, A. \& Kirk, K. (1996). Speech perception and performance in pediatric cochlear implant users. Seminars in Hearing, 17, 353-369.

Shipley, K. \& McAfee, J. (1992). Communicative disorders: An assessment manual. San Diego, CA: Singular Publishing Group.

Staller, S., Beiter, A., \& Brimacombe, J. (1994). Use of the nucleus 22 channel cochlear implant system with children. Volta Review, 96, 15-39. 
Tyler, R. (1993). Cochlear implants: Audiological foundations. San Diego, Ca: Singular Publishing Group.

Vermeulen, A. M., Beijk, C. M., Brokx, P. L., Van Den Broek, S, \& Van Den Broek, P. (1994). Development of speech perception abilities of profoundly deaf children: A comparison between children with cochlear implants and those with conventional hearing aids. Annals of Otology, Rhinology, \& Laryngology, 166 (suppl 4), 215-217. 